Article

\title{
Preparation of Molded Fiber Products from Hydroxylated Lignin Compounded with Lewis Acid-Modified Fibers Its Analysis
}

\author{
Tianhao Liu $\mathbb{1}$, Ying Wang, Jin Zhou, Mengyang Li and Jinquan Yue * \\ Key Laboratory of Bio-based Material Science \& Technology, Northeast Forestry University, \\ Ministry of Education, Harbin 150040, China; lth15145838960@163.com (T.L.); wangynefu@163.com (Y.W.); \\ zj15927490792@163.com (J.Z.); 15511313386@163.com (M.L.) \\ * Correspondence: yuejinq@nefu.edu.cn or yuejinq@163.com
}

check for updates

Citation: Liu, T.; Wang, Y.; Zhou, J.; Li, M.; Yue, J. Preparation of Molded Fiber Products from Hydroxylated Lignin Compounded with Lewis Acid-Modified Fibers Its Analysis. Polymers 2021, 13, 1349. https:// doi.org/10.3390/polym13091349

Academic Editor: Antonio Pizzi

Received: 14 January 2021

Accepted: 8 April 2021

Published: 21 April 2021

Publisher's Note: MDPI stays neutral with regard to jurisdictional claims in published maps and institutional affiliations.

Copyright: (c) 2021 by the authors. Licensee MDPI, Basel, Switzerland. This article is an open access article distributed under the terms and conditions of the Creative Commons Attribution (CC BY) license (https:// creativecommons.org/licenses/by/ $4.0 /)$.
Abstract: In this study, molded fiber products (MFPs) were prepared from lignin compounded with Lewis acid-modified fibers using enzymatic hydrolysis lignin (EHL) as a bio-phenol. The fibers were modified and compounded entirely through hot-pressing. To improve the reactivity of enzymatic lignin, hydroxylated enzymatic hydrolysis lignin (HEHL) was prepared by hydroxylation modification of purified EHL with hydrogen peroxide $\left(\mathrm{H}_{2} \mathrm{O}_{2}\right)$ and ferrous hydroxide $\left(\mathrm{Fe}(\mathrm{OH})_{3}\right)$. HEHL was mixed uniformly with Lewis acid-modified fibers on a pressure machine and modified during the molding process. The purpose of Lewis acid degradation of hemicellulose-converted furfural with HEHL was to generate a resin structure to improve the mechanical properties of a MFPs. The microstructure of the MFP was shown to be generated by resin structure, and it was demonstrated that HEHL was compounded on Lewis acid-modified fibers during the molding process. The thermal stability of the MFP with composite HEHL did not change significantly owing to the addition of lignin and had higher tensile strength ( $46.28 \mathrm{MPa})$ and flexural strength $(65.26 \mathrm{MPa})$ compared to uncompounded and modified MFP. The results of this study are expected to promote the application of high lignin content fibers in molded fibers.

Keywords: enzymatic hydrolysis lignin; hydroxylation; hemicellulose; molded fiber products; biocomposites

\section{Introduction}

In recent years, the depletion of fossil resources and the need for sustainable development have led to a great interest in biomass as a renewable energy source. The use of biomass materials (wood, straw, etc.) based on sustainable development principles has significantly improved [1,2]. Biomass composites and their preparation processes have shown high potential owing to their wide range of advantageous properties; among common biomass materials, wood is widely used as a representative renewable biological resource [3]. The raw material of molded fiber products (MFPs) is generally chemical pulp (wood pulp, reed pulp, etc.), which is processed using a unique process and special additives in the mold compression molding of a class of three-dimensional fiber products $[4,5]$. MFPS have been developed rapidly as packaging materials alternative to plastic and solid wood owning to their high three-dimensional molding capability, good mechanical properties and great modification potential [6-8].

The mechanical strength of MFPs is generally thought to result from hydrogen bonding between fibers [9], condensation reactions of lignin in the fiber during the molding process [10], condensation of lignin, and partial degradation of hemicellulose [11]. Therefore, the polymers in the raw materials of MFPs, i.e., cellulose, hemicellulose and lignin, are of particular importance. Cellulose, as the main component of MFPs, should ensure that the fiber properties are not changed significantly during preparation. Therefore, drastic 
preparation conditions should not be used [12]. As a natural polymeric material with phenylpro-pane as structural monomer, lignin is considered the most promising alternative to phenol-targeted adhesives owing to the presence of hydroxyl groups [13]. The complex structure of lignin as well as the presence of spatial site resistance leads to low reactivity. Increasing the lignin hydroxyl content by chemical means while decreasing the molecular weight facilitates the condensation of lignin in the molding process [14]. Hemicellulose, which is a low molecular weight polysaccharide with a loose structure, is easily hydrolyzed into monomeric compounds (furfural, hydroxymethylfurfural, etc.) during the molding process [15]. Generated furfural-like substances have been reported to replace formaldehyde in the preparation of phenolic resins for composites and to react with phenols in acidic environments to produce biomass-based phenolic resins [16]. Furthermore, addition of lignin has been shown to improve the mechanical properties of MFPs.

In this study, we investigated the effect of a high content of lignin as a filler to be compounded with fibers on the mechanical strength of MFPs. EHL, which is suitable as the MFP filler owing to its high yield and low price, was extracted from corn cob using cellulase degradation. According to the literature, EHL is generally used to prepare lignin-based resins $[17,18]$ and polyurethane foams $[19,20]$, without being studied as a filler compounded into MFPs. Therefore, we focused on the modification and compounding of fibers during the molding process.

\section{Materials and Methods}

\subsection{Experimental Materials}

Enzymatic hydrolysis lignin (EHL) was purchased from Shandong Longlive Biotechnology Co., Ltd. (Shandong, China). Poplar wood chips were taken from the experimental forestry field of Northeast Forestry University. 1,4-Dioxane (AR, 99.7\%), ethyl ether (AR, 99.7\%), 30\% hydrogen peroxide (AR, $\geq 30 \%$ ), acetic anhydride (AR, 99.7\%), sodium hydroxide (AR, 99.7\%), phthalic anhydride (AR, 99.7\%), pyridine (AR, 99.7\%), phenol (AR, 99.7\%), and sodium carbonate (AR, 99.7\%) were purchased from Tianjin Fuyu Fine Chemical Co., Ltd. (Tianjin, China). Ferrous hydroxide (AR, 99.8\%) and cationic polyacrylamide (CPAM, AR, 99.7\%) were purchased from Shanghai Macklin Biochemical Co., Ltd. (Shanghai, China). Folin-Ciocalteu (FC) phenol reagent (1 mol/L) was purchased from Shanghai Lanji Technology Development Co., Ltd. (Shanghai, China). Tetrahydrofuran (THF, HPLC, 99.9\%) was purchased from Tianjin Starmark Science and Technology Development Co., Ltd. (Tianjin, China). Ferric chloride (AR, 99.7\%) and glacial acetic acid (AR, 99.7\%) were purchased from Tianjin Hengxing Chemical Reagent Co., Ltd. (Tianjin, China).

\subsection{EHL Refining}

Raw EHL was sieved using a standard sieve, and particles below 60 mesh were collected and dried in an oven at $80{ }^{\circ} \mathrm{C}$ for $12 \mathrm{~h}$. EHL was purified using 1,4-dioxane [21]. EHL (10 g) was dissolved in dioxane/water solution $(9 / 1, v / v, 100 \mathrm{~mL})$. Once the lignin dissolved completely, the solution was centrifuged, and the filtrate was collected. Then, the filtrate was dropped into ethyl ether $(300 \mathrm{~mL})$ and settled in a dark environment for $12 \mathrm{~h}$. The precipitate was collected after washing with deionized water; it was dried at $50{ }^{\circ} \mathrm{C}$ under vacuum, grinded and set as reserve.

\subsection{EHL Hydroxylation Modification}

We dissolved $20 \mathrm{~g}$ of EHL in $200 \mathrm{~mL}$ of sodium hydroxide solution $(1 \%, w / w)$ and transferred the solution to a three-necked flask. Then, $\mathrm{Fe}(\mathrm{OH})_{3}(0.02 \mathrm{~g})$ and $30 \% \mathrm{H}_{2} \mathrm{O}_{2}(24 \mathrm{~g})$ solution were added under stirring conditions. The reaction was carried out in a water bath $\left(50^{\circ} \mathrm{C}\right)$ after installing a reflux condenser. As reactions completed, the $\mathrm{Fe}(\mathrm{OH})_{3}$ residue was removed by centrifugation. The $\mathrm{pH}$ of the filtrate was adjusted to 1 with hydro-chloric acid solution $(12 \%, w / w)$ to precipitate. The precipitated fraction was washed with deionized water and then freeze-dried and grinded to hydroxylated EHL (HEHL). 


\subsection{Preparation of $M F P$}

Poplar wood chips were impregnated with sodium hydroxide solution $(8 \%, w / v)$ for $2 \mathrm{~h}$ at $100{ }^{\circ} \mathrm{C}$ and then separated into fibers by a split corotating twin-screw extruder to obtain a chemithermomechanical pulp (CTMP) [22].

The base weight of MFP is $1000 \mathrm{~g} / \mathrm{m}^{2}$. The CTMP fibers $(10.5 \mathrm{~g})$ were placed in a mixed solution $(300 \mathrm{~mL})$ of acetic acid $(3 \%, v / v)$ and $\mathrm{FeCl}_{3}(0.03 \mathrm{~mol} / \mathrm{L})$ for 10 min by maceration. Then, $1 \mathrm{~g}$ of CPAM $(1 \%, w / w)$ solution was added and dispersed using a fiber sparger. Once the dispersion became uniform, EHL (1.575 g) was added for further dispersion. The mixture was transferred to a mold by Vacuum dehydration and pre-pressure to adjust the moisture content of the sample to $70 \%$. Hot-pressing was carried out at $180{ }^{\circ} \mathrm{C}$ and $4 \mathrm{MPa}$ for $20 \mathrm{~min}$ to obtain HELS. Table 1 lists the names of the control group samples prepared in this study.

Table 1. Names given to the control group samples.

\begin{tabular}{cc}
\hline Sample & Abbreviation \\
\hline CTMP fibers & CS \\
CTMP fibers \& CPAM & CCS \\
CTMP fibers, CPAM \& EHL & ES \\
CTMP fibers, CPAM \& HEHL & HES \\
Lewis acid-modified CTMP fiber & LS \\
Lewis acid-modified CTMP fiber, CPAM \& EHL & ELS \\
Lewis acid-modified CTMP fiber, CPAM \& HEHL & HELS
\end{tabular}

CTMP, chemithermomechanical pulp; CPAM, cationic polyacrylamide; EHL, enzymatic hydrolysis lignin; HEHL, hydroxylated enzymatic hydrolysis lignin.

The MFPs listed in Table 1 were pre-pressed using a PL8-B molding equipment (Xianyang Taist Test Equipment Co., Ltd. (Xianyang, China)) and hot-pressed using a ZG-20T pressure machine (Dongguan Zhengyong Electronic Mechanical Ltd. (Dongguan, China)).

\subsection{Characterization}

The micromorphology of the samples was analyzed using scanning electron microscopy (SEM, COXEM EM-30, COXEM Co., Ltd., Daejeon, Korea). Functional group changes were analyzed using Fourier transform infrared (FTIR) spectroscopy (VERTEX80, Bruker, Billerica, MA, USA). The content of each element of the EHL was analyzed using an Elemantar Vario EL cube (Elementar Analysensysteme GmbH, Langenselbold, Germany) organic elemental analyzer. EHL was acetylated according to the method of Pereira Araujo et al. [23]. The molecular weight of EHL was analyzed using ambient gel permeation chromatograph (GPC, Agilent PL-GPC50 am, Agilent Technologies, Inc., Santa Clara, CA, USA) with polystyrene (PS) specimens with molecular weights of 6,570,000, 3,152,000, 920,000, 468,300, 9820, 4910, 1300, 580 and $162 \mathrm{~g} / \mathrm{mol}$. A lignin/THF solution $(1 \mathrm{mg} / \mathrm{mL})$ was prepared and insoluble material was removed before performing the GPC assay using a $0.22 \mu \mathrm{m}$ filter membrane. The flow rate was $1 \mathrm{~mL} / \mathrm{min}$ and the injection volume was $25 \mu \mathrm{L}$. A thermogravimetric analysis (TGA, TGA5500 thermogravimetric analyzer, TA INSTRUMENTS, New Castle, DE, USA) was performed to examine the thermogravimetric curves of EHL and MFPs before and after modification with a sampling mass of $5.5 \mathrm{mg}$. The test temperature was increased from 30 to $795{ }^{\circ} \mathrm{C}$ at a heating rate of $10^{\circ} \mathrm{C} / \mathrm{min}$ under nitrogen atmosphere $(10 \mathrm{~mL} / \mathrm{min})$.

The 2D-NMR analysis was made at $25^{\circ} \mathrm{C}$ in a Bruker Avance $600 \mathrm{MHz}$ spectrometer (Bruker, Karlsruhe, Germany). Approximately $30 \mathrm{mg}$ of lignin samples were dissolved in $0.50 \mathrm{~mL}$ of DMSO- $d_{6}$. HSQC experiments used Bruker's "hsqcetgp" pulse program with spectral widths of 3400 and $18,700 \mathrm{~Hz}$ for the ${ }^{1} \mathrm{H}$ and ${ }^{13} \mathrm{C}$ dimensions. The number of collected complex points was 1024 for the ${ }^{1} \mathrm{H}$ dimension with a recycle delay of $1.5 \mathrm{~s}$. The number of transients was 257, and 256 time increments were recorded in the $13 \mathrm{C}$ dimension. Processing used typical matched sine square $90^{\circ}$ apodization in ${ }^{1} \mathrm{H}$ and ${ }^{13} \mathrm{C}$. HSQC spectra 
were processed with MestReNova, v14.0.0-23239 software (Mestrelab Research, Spain). Prior to Fourier transformation, the data matrices were zero-filling up to 2048 points in the ${ }^{1} \mathrm{H}$ and ${ }^{13} \mathrm{C}$ dimensions. For correct peak integration, the spectra were previously baseline-corrected with the default option. The central solvent peak was used as an internal reference $\left(\delta_{\mathrm{C}} 40.03 ; \delta_{\mathrm{H}} 2.48\right)$.

\subsection{Determination of Hydroxyl Content}

The alcohol hydroxyl content was measured according to ISO14900 (2017). We dissolved $100 \mathrm{mg}$ of EHL in $25 \mathrm{~mL}$ of phthalic anhydride acylation reagent. The solution was transferred to a conical flask with a condensing reflux device, which was then placed in a $115^{\circ} \mathrm{C}$ oil bath for $0.5 \mathrm{~h}$. We washed the condensing unit with pyridine at the end of the reaction and transferred the solution to a $1000 \mathrm{~mL}$ conical flask. Then, the solution was diluted with $500 \mathrm{~mL}$ of distilled water; $0.5 \mathrm{~mL}$ of phenolphthalein indicator was added and then titrated using sodium hydroxide solution $(1.0 \mathrm{~mol} / \mathrm{L})$ under magnetic stirring conditions. Moreover, blank experiments were performed as described above.

The phenolic hydroxyl content assay was performed using the FC method [24]. Using a pipette, we added $10 \mathrm{~mL}$ of phenol solution $(2.14 \mathrm{mmol} / \mathrm{L})$ into $100 \mathrm{~mL}$ volumetric flask and fixed the volume. We transferred $0,1,2,4,8,10$, and $14 \mathrm{~mL}$ of the above solution to a $50 \mathrm{~mL}$ volumetric flask (the concentrations were $0,4.278,8.556,17.112,34.224,42.780$, and $59.892 \mu \mathrm{mol} / \mathrm{L}$, respectively). Then, we added FC reagent ( $3 \mathrm{~mL})$ and 30, 29, 28, 26, 20, and $16 \mathrm{~mL}$ of distilled water, followed by full shaking for $30 \mathrm{~s}$. Further, we added $10 \mathrm{~mL}$ of $\mathrm{Na}_{2} \mathrm{CO}_{3}(20 \%, w / v)$ solution; then, we mixed the solution uniformly and fixed it with distilled water. The above mixture was reacted with magnetic stirring at room temperature for $2 \mathrm{~h}$ to obtain a series of reaction products. The final absorbance of the product was measured at $760 \mathrm{~nm}$ and the concentration-absorbance standard curve was plotted.

Next, we accurately weighed $100 \mathrm{mg}$ of dried EHL specimen and dissolved it in $100 \mathrm{~mL} \mathrm{NaOH}(1 \mathrm{~g} / \mathrm{L}, w / v)$. We transferred $500 \mu \mathrm{L}$ of the solution to a $50 \mathrm{~mL}$ volumetric flask. Then, we added FC reagent $(3 \mathrm{~mL})$ and distilled water $(30 \mathrm{~mL})$. After shaking for 5-8 min, we added $10 \mathrm{~mL}$ of $\mathrm{Na}_{2} \mathrm{CO}_{3}(20 \%, w / v)$ and fixed the solution with $50 \mathrm{~mL}$ of distilled water. The mixture was stirred for $2 \mathrm{~h}$ before the measurements. The absorbance of a blank sample with a phenol concentration of 0 was used to determine at $760 \mathrm{~nm}$ as a reference. The measured absorbance was plotted against the concentration-absorbance standard curve in order to calculate the phenolic hydroxyl content.

\subsection{Mechanical Properties of MFP}

The density of the MFPs was determined according to ISO 534 (2011). Strips of $100 \mathrm{~mm} \times 15 \mathrm{~mm}$ were cut for tensile testing, and strips of $100 \mathrm{~mm} \times 25 \mathrm{~mm}$ were cut for bending testing. The mechanical strength was tested with a CMT5504 universal strength testing machine (Shenzhen SANS Testing Machine Co., Ltd. (Shenzhen, China)) according to ISO 527-3 (2018) and ISO 178 (2019) standards. The average of five measurements for each group of samples was reported as the result.

\section{Result and Discussion}

\subsection{Characterization of Lignin}

3.1.1. Micromorphology of EHL

Figure 1 shows SEM images of the EHL taken to determine the changes in the micromorphology of EHL during the hydroxylation modification process. From the figure, it can be seen that the surface of purified EHL is rough and has many pores, while the surface of $\mathrm{HEHL}$ is relatively smooth. It is presumed that the molecular weight of the modified EHL decreases and the content of hydroxyl groups increases, which causes the micromorphology changes due to the degradation of the surface molecules of EHL by $\mathrm{H}_{2} \mathrm{O}_{2}$. 

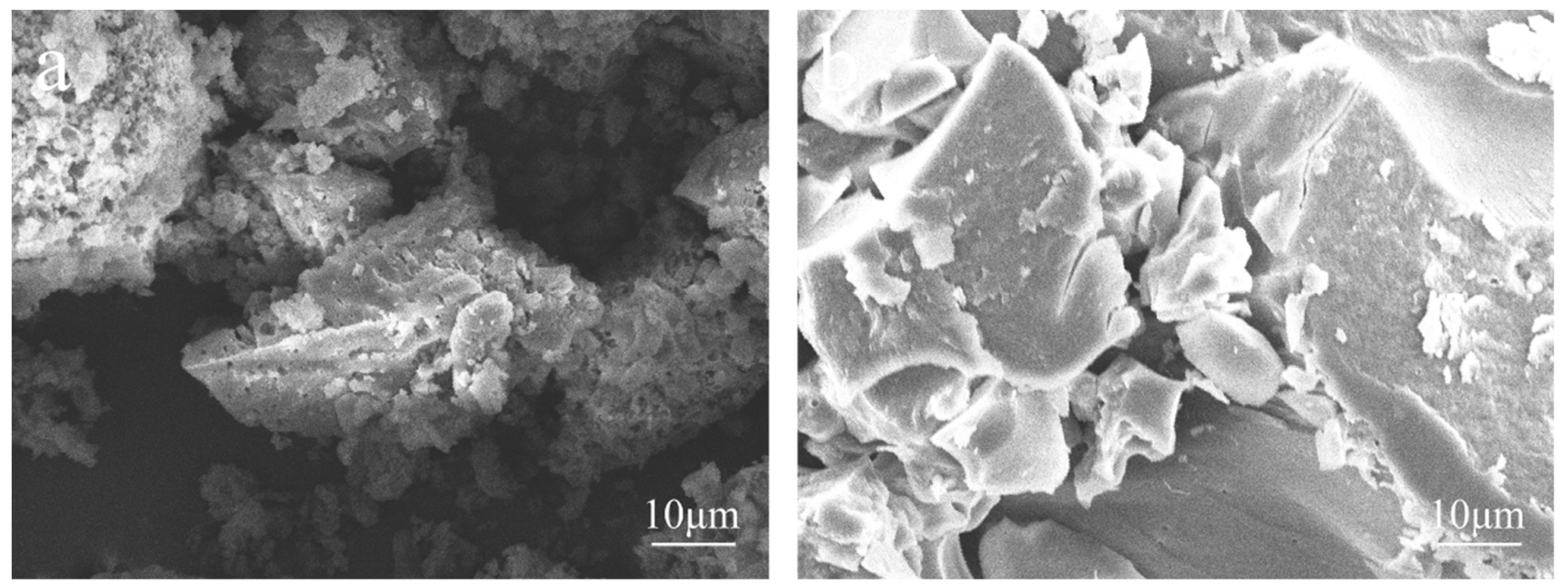

Figure 1. SEM images of (a) EHL and (b) HEHL at $\times 2000$ magnification.

\subsubsection{GPC of EHL and HEHL}

The GPC curves of the soluble components of EHL and HEHL are shown in Figure 2 and Table 2. After hydroxylation modification, $\mathrm{M}_{\mathrm{w}}$ of EHL decreased from 16,900 to 12,600 and its $M_{n}$ decreased from 2900 to 2800. The decrease in $M_{w}$ indicates the conversion to relatively small molecules during the modification process. The breakage of the ether bond was accompanied by the generation of a large number of hydroxyl groups, resulting in the decrease in the relative molecular mass of EHL. The distribution index $\left(M_{w} / M_{n}\right)$, which is an indicator of polydispersity, of the EHL and HEHL samples measured by GPC, was 5.83 and 4.50 , respectively. The decrease in the distribution width index indicates that the relative molecular mass of HEHL is more uniformly distributed. In Figure 2, the area changes of the molecular weight distribution curves of EHL and HEHL indicate that the molecular weight distribution of HEHL becomes more uniform. The uniformity of the relative molecular mass distribution of EHL is beneficial for its application in subsequent experiments.

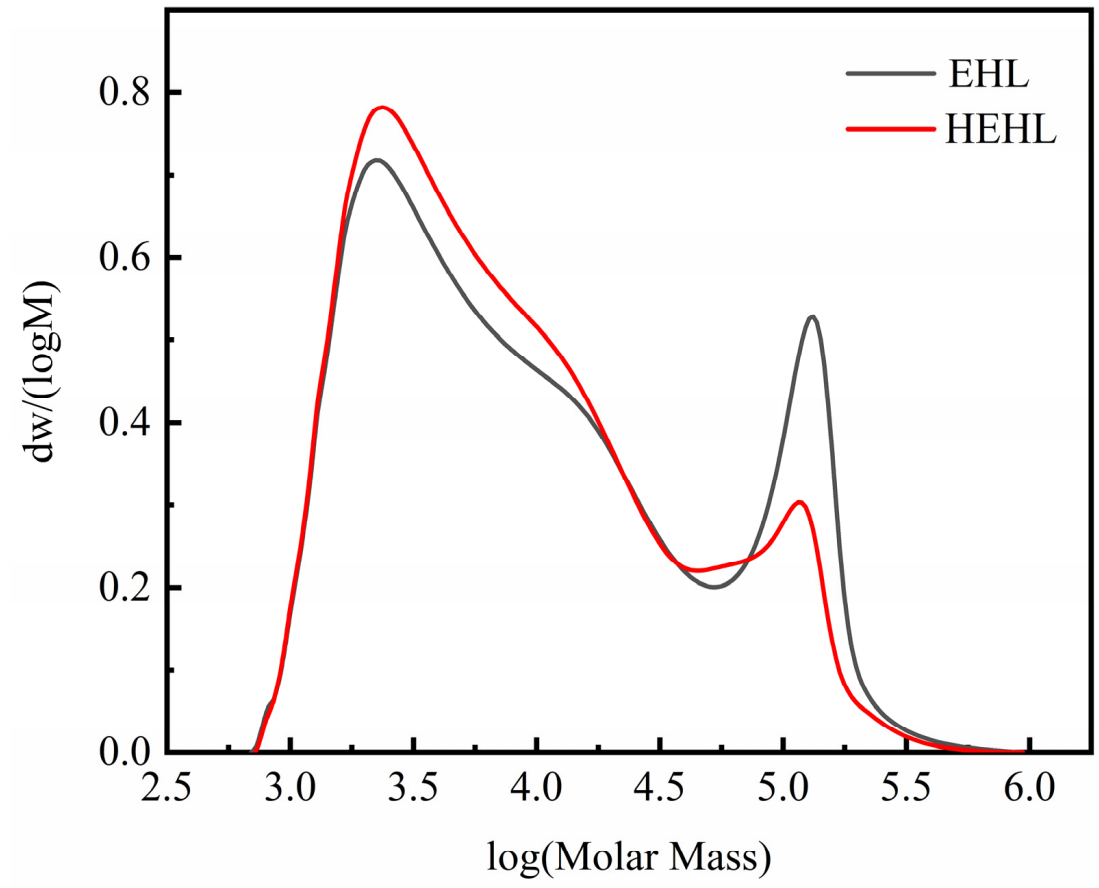

Figure 2. Molecular weight distribution curves of EHL and HEHL samples. 
Table 2. Gel permeation analysis for EHL and HEHL.

\begin{tabular}{ccc}
\hline GPC & EHL & HEHL \\
\hline $\mathrm{M}_{\mathrm{w}}(\mathrm{g} / \mathrm{mol})$ & 16,900 & 12,600 \\
$\mathrm{M}_{\mathrm{n}}(\mathrm{g} / \mathrm{mol})$ & 2900 & 2800 \\
Distribution index & 5.83 & 4.50 \\
\hline
\end{tabular}

\subsubsection{Hydroxyl Content of EHL}

Figure 3 shows plots of the hydroxyl content of HEHL as a function of the reaction temperature, time and material/liquid ratio. The experimental parameters for the hydroxylation modification of EHL are $50{ }^{\circ} \mathrm{C}, 80 \mathrm{~min}, 1.2$ mass ratio of $\mathrm{H}_{2} \mathrm{O}_{2}$ to $\mathrm{EHL}$, and 0.01 mass ratio of $\mathrm{Fe}(\mathrm{OH})_{3}$ to EHL. The hydroxyl content of HEHL was prepared under the above conditions, which change as shown in Table 3. The alcohol hydroxyl content, phenolic hydroxyl content, and total hydroxyl content of HEHL were $2.94 \%, 1.05 \%$, and $3.99 \%$ higher than those of EHL. Given the satisfactory results, the above experimental conditions were not optimized further and were applied to subsequent experiments.
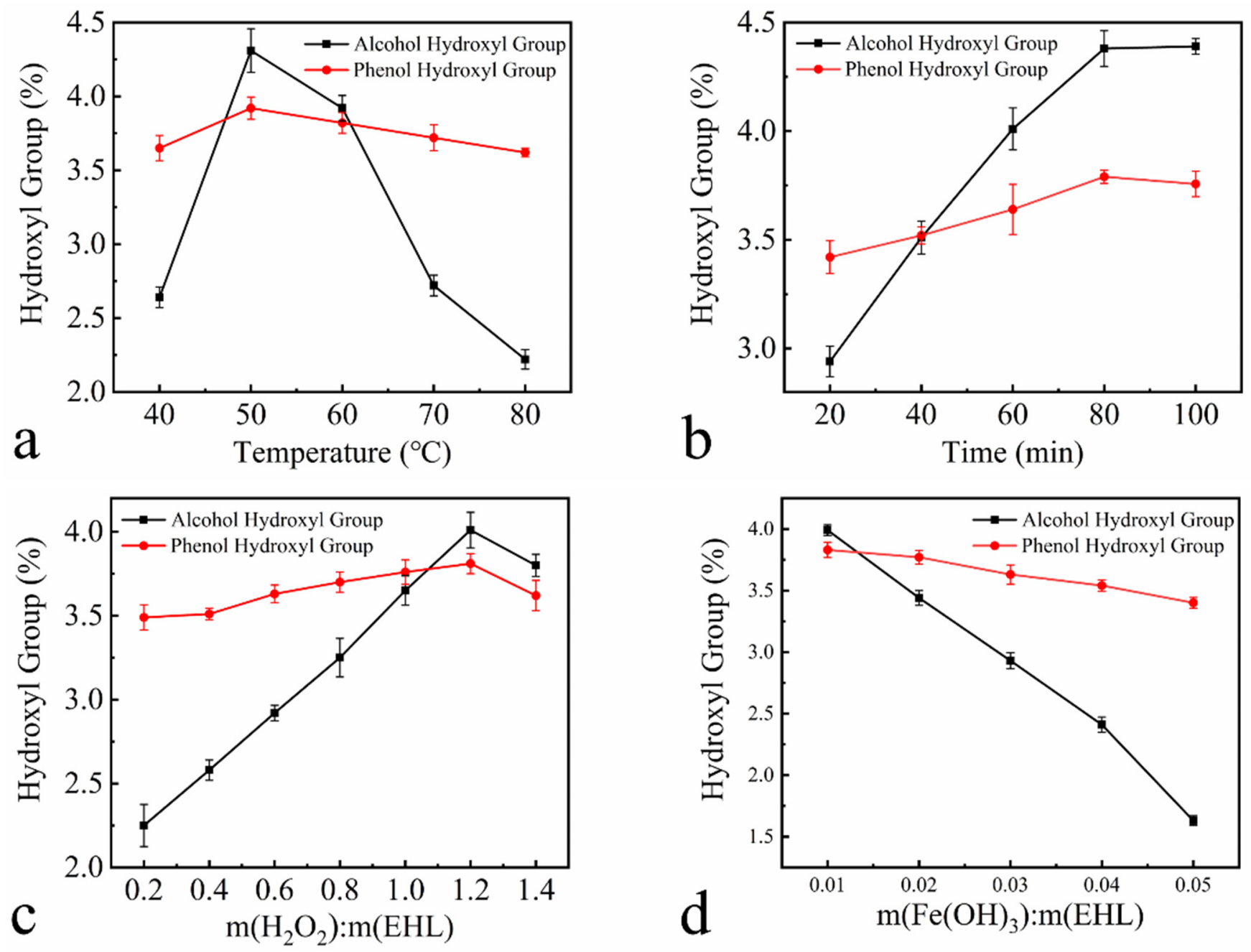

Figure 3. Variation of hydroxyl group content with the following factors: (a) temperature at $m\left(\mathrm{H}_{2} \mathrm{O}_{2}\right): \mathrm{m}(\mathrm{EHL})=1: 1$, $\mathrm{m}\left(\mathrm{Fe}(\mathrm{OH})_{3}\right): \mathrm{m}(\mathrm{EHL})=0.01: 1$, and $60 \mathrm{~min}$ reaction time; $(\mathbf{b})$ time at $\mathrm{m}\left(\mathrm{H}_{2} \mathrm{O}_{2}\right): \mathrm{m}(\mathrm{EHL})=1: 1 ; \mathrm{m}\left(\mathrm{Fe}(\mathrm{OH})_{3}\right): \mathrm{m}(\mathrm{EHL})=0.01: 1$, and $50{ }^{\circ} \mathrm{C}$ reaction temperature; $\left(\right.$ c) $\mathrm{H}_{2} \mathrm{O}_{2}$ content at $\mathrm{m}\left(\mathrm{Fe}(\mathrm{OH})_{3}\right): \mathrm{m}(\mathrm{EHL})=0.01: 1 ; 60{ }^{\circ} \mathrm{C}$ reaction temperature, and $60 \mathrm{~min}$ reaction time; $(\mathbf{d}) \mathrm{Fe}(\mathrm{OH})_{3}$ content at $\mathrm{m}\left(\mathrm{H}_{2} \mathrm{O}_{2}\right): \mathrm{m}(\mathrm{EHL})=1: 1,60{ }^{\circ} \mathrm{C}$ reaction temperature, 60 min reaction time. All data in Figure 3 are based on three parallel experiments. 
Table 3. Hydroxyl content of EHL and HEHL.

\begin{tabular}{cccc}
\hline Sample & Alcohol Hydroxyl Group (\%) & Phenol Hydroxyl Group (\%) & Total (\%) \\
\hline EHL & 2.24 & 3.11 & 5.35 \\
HEHL & 5.18 & 4.16 & 9.34 \\
\hline
\end{tabular}

\subsubsection{Chemical Composition and Structure of EHL}

Figure 4 shows the FTIR spectra of the EHL and HEHL spectra, and Table 4 lists the absorption peaks. From Figure 4, it can be seen that the width of the absorption peak of the stretching vibration of the hydroxyl group $(-\mathrm{OH})$ of HEHL did not vary significantly in the range of 3500-3340 $\mathrm{cm}^{-1}$ [25]. Therefore, it needs to be proven by other testing methods. A comparison of the four absorption peaks at 1594, 1507, 1457, and $1420 \mathrm{~cm}^{-1}$ [26] shows that the aromatic ring skeleton of HEHL is the same as that of EHL, and only the linkage bonds between the aromatic rings are broken. The increase in hydroxyl content was also verified by analyzing the organic element content (Table 5).

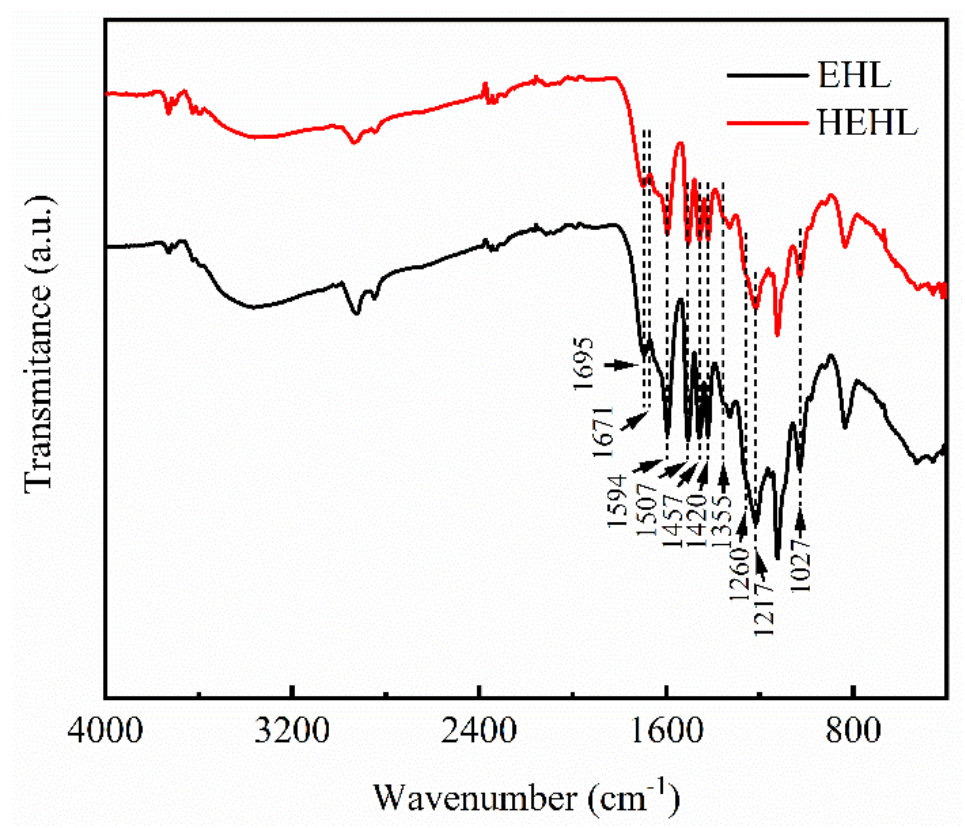

Figure 4. Fourier transform infrared (FTIR) spectra of EHL and HEHL in the $4000-400 \mathrm{~cm}^{-1}$ range.

Table 4. Band Assignments for FTIR of EHL and HEHL.

\begin{tabular}{cc}
\hline Wavenumber $\left(\mathbf{c m}^{-\mathbf{1}}\right)$ & Assignment \\
\hline $3500-3340$ & OH groups stretching \\
$2975-2875$ & C-H stretching \\
$1695 / 1671$ & C=O stretching \\
1594 & C-C stretching and aromatic vibrations \\
$1507 / 1457$ & Aromatic ring vibration \\
1420 & C-H bending \\
1355 & H-O bending \\
$1260 / 1217$ & Conjugated C-O \\
1027 & Unconjugated C-O \\
\hline
\end{tabular}

Table 5. Organic element content of EHL and HEHL.

\begin{tabular}{cccccc}
\hline Sample & $\mathbf{N}(\%)$ & $\mathbf{C ~ ( \% )}$ & $\mathbf{H ~ ( \% )}$ & $\mathbf{S ~ ( \% )}$ & $\mathbf{O}(\mathbf{\%})$ \\
\hline EHL & 1.02 & 62.14 & 5.58 & 0.11 & 29.63 \\
HEHL & 1.04 & 60.67 & 5.82 & 0.12 & 31.27 \\
\hline
\end{tabular}




\subsubsection{Thermostability Analysis of EHL}

Figure 5 shows the TGA results of EHL and HEHL.
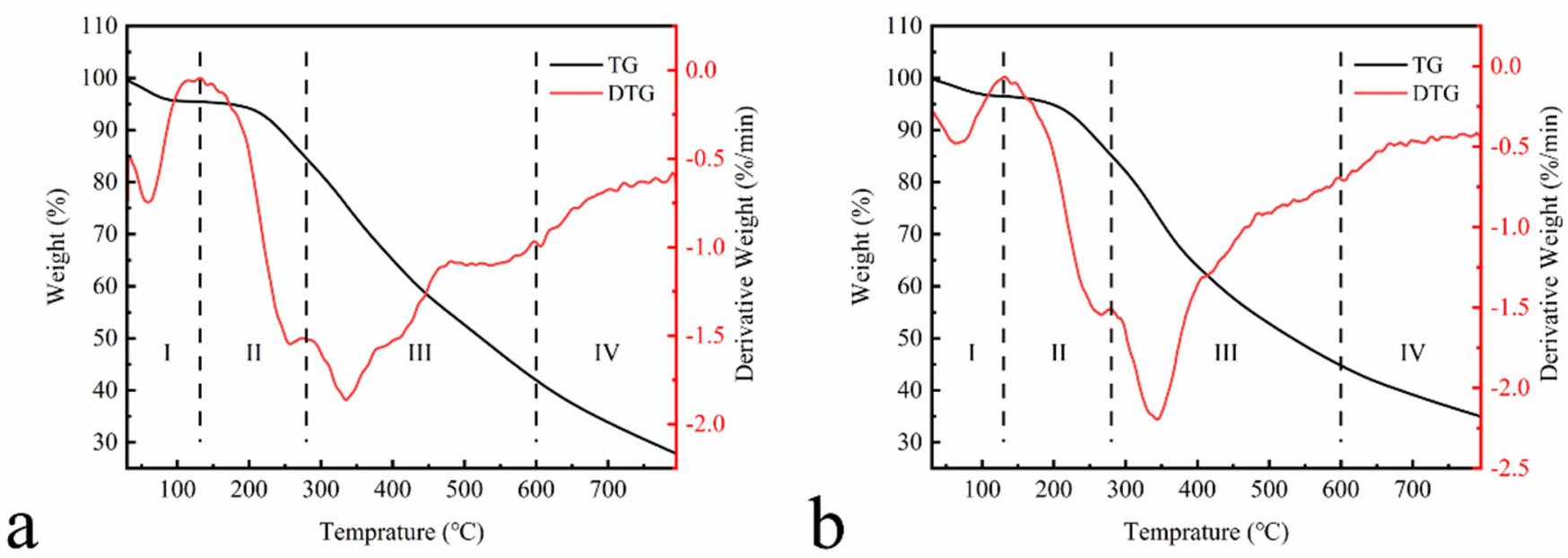

Figure 5. Thermogravimetric analysis of (a) EHL and (b) HEHL in the temperature range of $30-795^{\circ} \mathrm{C}$ with a heating rate of $10{ }^{\circ} \mathrm{C} / \mathrm{min}$ under nitrogen atmosphere $(10 \mathrm{~mL} / \mathrm{min})$.

The TGA of lignin samples was performed between 30 and $795^{\circ} \mathrm{C}$ under a nitrogen atmosphere. The thermal weight loss process of the samples was divided into four stages. In Stage I (30-130 $\left.{ }^{\circ} \mathrm{C}\right), \mathrm{EHL}$ and HEHL have the same trend. This is attributed to the evaporation of adsorbed water, crystalline water, and organic small molecule components in the lignin. At $60{ }^{\circ} \mathrm{C}$, the maximum dehydration rate of EHL and HEHL reached 0.745 and $0.478 \% / \mathrm{min}$. In Stage II $\left(130-280{ }^{\circ} \mathrm{C}\right)$, the weight loss of lignin is related to the bond breakage of the lower dissociation energy in the lignin structure. In stage III $\left(280-600{ }^{\circ} \mathrm{C}\right)$, lignin degrades gradually with the increasing temperature. There is a $42.61 \%$ and $40.36 \%$ weight loss of EHL and HEHL, respectively, in the third stage from 280 to $600{ }^{\circ} \mathrm{C}$, which is the most significant range of thermal decomposition. The presence of a large number of linkages (e.g., hydroxyl, carbonyl, and other linkages) in lignin results in a wide range of EHL degradation temperatures. At $335.09{ }^{\circ} \mathrm{C}$, the weight loss rate of the EHL reaches the maximum value of $1.86 \% / \mathrm{min}$. Moreover, the weight loss rate of HEHL reached a maximum value of $2.16 \% / \mathrm{min}$ at $333.19^{\circ} \mathrm{C}$, indicating increased intramolecular hydrogen bonding and structural changes. Therefore, HEHL has slightly improved thermal stability compared to EHL. In Stage IV $\left(600-795^{\circ} \mathrm{C}\right)$, the TGA curve stabilizes. The breakage and condensation of aromatic rings mainly occurred in this stage. However, the weight loss is not significant, suggesting that the thermal decomposition process is over. The percentage of residual carbon after thermal degradation of EHL and HEHL was $27.88 \%$ and $34.98 \%$, respectively.

\subsection{Characterization of MFP}

\subsubsection{Micromorphology of MFP}

Figure 6 shows SEM images of the MFP captured to investigate the bonding of lignin during the modification of MFP by EHL composite Lewis acid.

As shown in Figure 6a,b, the CCS fibers are tightly interwoven and have a smooth surface compared with the CS fibers, indicating that the addition of CPAM as a filtering agent did not change the basic morphology of the MFP. It is presumed that the addition of CPAM does not affect the bonding strength between fibers. As shown in Figure $6 \mathrm{a}, \mathrm{c}, \mathrm{d}$, a layer of lignin was compounded on the surface and between the fibers of ES and HES fibers uniformly than on the CS. The different lignin micromorphology on the fiber surface is attributed to the different hydroxyl content of EHL and HEHL, which also leads to a different enhancement of the mechanical strength of the MFP. As shown 
in Figure 6a,e, compared to CS, LS fibers modified with Lewis acid during the molding process showed scale-like microstructures due to hemicellulose degradation on the surface, which facilitated the hydrogen bonding between fibers. Comparable to CS, lignin was more uniformly distributed on the fiber surface and between the fibers according to the scale-like microfiber structure of Lewis acid-modified fibers, as shown in Figure 6a,f,g.
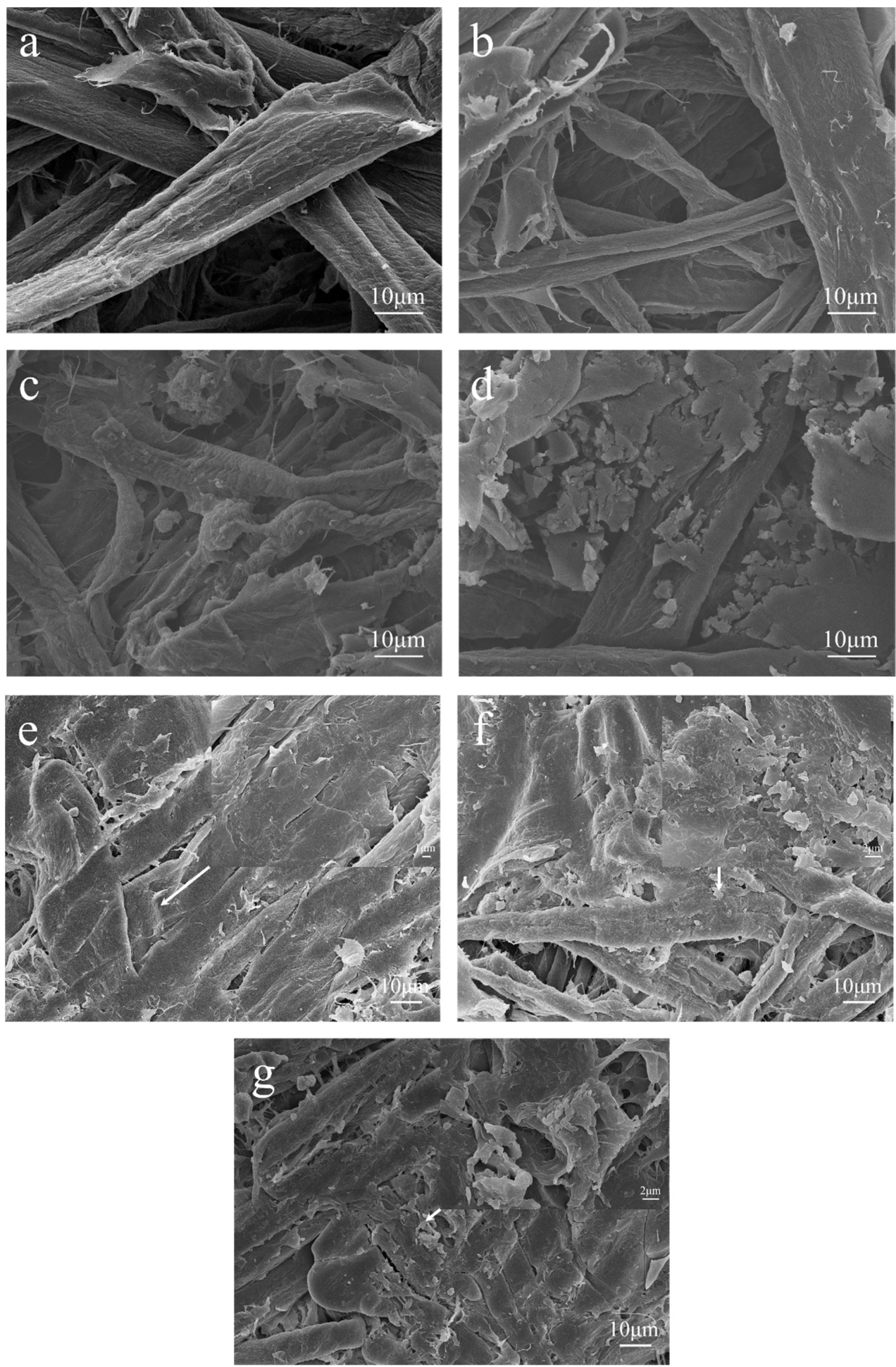

Figure 6. SEM images of the various MFP samples at $\times 2000$ magnification: (a) CS; (b) CCS; (c) ES; (d) HES; (e) LS; (f) ELS; (g) HELS. 


\subsubsection{Chemical Composition and Structure of MFP}

The mechanical performance of an MFP depends on its chemical structure. Therefore, we verified the cross-linking properties of EHL with Lewis acid-modified fibers by FTIR spectroscopy. Figure 7 shows the FTIR spectra of CS, CCS, ES, HES, LS, ELS, and HELS, and Table 6 summarizes the assignments of each spectrum, according to the results reported in [27-29]. The absorption peaks of the above samples in the range of $3500-3200 \mathrm{~cm}^{-1}$ were assigned to the stretching vibration of $-\mathrm{OH}$. The broad absorption peaks at 1709 and $1652 \mathrm{~cm}^{-1}$ in the MFP are related to the non-conjugated and conjugated $\mathrm{C}=\mathrm{O}$ stretching vibration, respectively. This was attributed to the degradation of some hemicellulose into furfural by Lewis acid during the molding process and its own condensation. The peaks at $1592,1507,1457$, and $1420 \mathrm{~cm}^{-1}$ belong to the characteristic vibration of the aromatic and furan rings. The absorption peak intensity of CCS was lower than that of CS owing to the addition of CPAM on the fiber surface. The signal of the above absorption peaks is enhanced by the presence of aromatic rings in the structure of the lignin added in ES and HES. The degradation of some hemicelluloses in the Lewis acid-modified fibers to furfural as a furan ring structure led to the enhancement of the above absorption peak signal in LS compared with that of CS. For the ELS and HELS, in a Lewis acid environment, lignin reacts with furfural produced during the molding process to form a phenolic resin-like structure and further enhance the above signal peaks. Peaks at 1270, 1230, 1050, and $1030 \mathrm{~cm}^{-1}$ belong to the characteristic vibration of the C-O stretching vibration peaks. The appearance of the above absorption peaks proves that the lignin added during the molding process introduces a phenolic cross-linking system by reacting with furfural generated by the degradation of hemicellulose. The ELS and HELS spectra have characteristic absorption peaks at 835 and $770 \mathrm{~cm}^{-1}$ attributed to the nucleophilic substitution reaction of lignin [30]. This suggests that a phenolic resin-like structure is generated during the molding process.
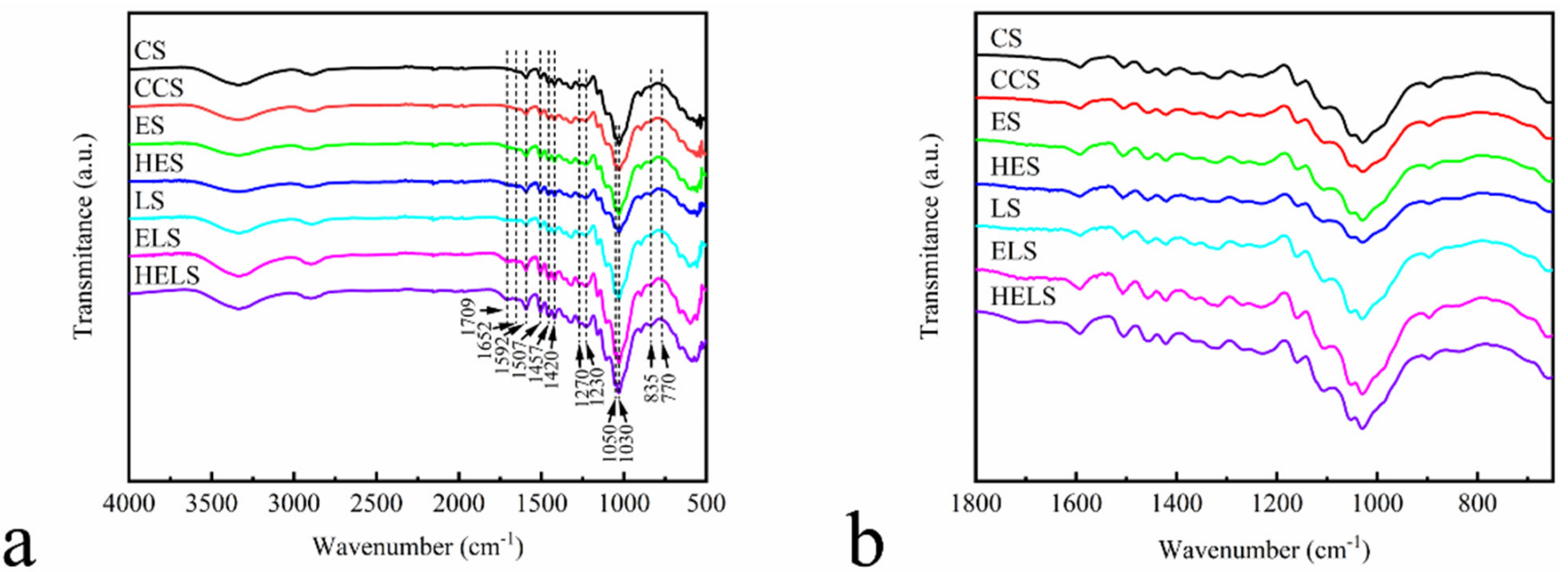

Figure 7. Fourier transform infrared (FTIR) analyses of MFP in the $4000-500 \mathrm{~cm}^{-1}$ range: (a) Full FTIR spectrogram; (b) FTIR spectrogram between 1800 and $650 \mathrm{~cm}^{-1}$.

\subsubsection{Thermostability of MFP}

The TGA curves of CS, CCS, ES, HES, LS, ELS, and HELS are shown in Figure 8. The results showed that the pyrolysis efficiency of all MFP samples was basically the same in the temperature range of $30-795^{\circ} \mathrm{C}$. As shown in Figure 8, the trends of TGA curves for all samples were generally consistent. There is $2-3 \%$ weight loss in the first segment from 30 to $115{ }^{\circ} \mathrm{C}$. This is attributed to the evaporation of residual water, physical adsorption water, and crystalline water in the MFP samples. A platform with no weight loss can be obtained in the range of 115 to $200{ }^{\circ} \mathrm{C}$, as the water of the MFP sample has completely evaporated, and no pyrolysis of the MFP sample occurs. As the temperature increases, 
the MFP samples gradually undergo thermal degradation. There is an approximately $65 \%$ weight loss in the second segment from 200 to $380^{\circ} \mathrm{C}$, which is the most significant range of thermal decomposition. Under such heat conditions, glucosyl, and glycosidic bonds, are dramatically cleaved. Small molecules of gases including carbon monoxide and carbon dioxide are released. The TGA curve decreases rapidly, and the weight loss rate increases gradually. Subsequently, the deep thermal degradation of the fibers occurred from 380 to $795^{\circ} \mathrm{C}$, and the pyrolysis of the residual material continued. For lignin, furfural and its condensates are mainly produced in this stage. However, the final residual material content varied from sample to sample. The residual material of HELS was higher than that of CS due to the structure of the furfural-generating resin produced by the degradation of lignin and hemicellulose.

Table 6. Band Assignments for FTIR of MFP.

\begin{tabular}{cc}
\hline Wavenumber $\left(\mathbf{c m}^{-\mathbf{1}}\right)$ & Assignment \\
\hline $3500-3200$ & OH groups stretching \\
$2950-2850$ & C-H stretching \\
1709 & Unconjugated C=O stretching \\
1652 & Conjugated C=O stretching \\
1592 & C-C stretching and aromatic ring structure stretching \\
$1507 / 1457$ & Aromatic and furan ring structure stretching \\
1420 & C-H bending \\
$1270 / 1230$ & Conjugated C-O stretching \\
$1050 / 1030$ & Unconjugated C-O stretching \\
835 & C-H out-of-plane bending, para-substituted \\
770 & C-H out-of-plane bending, ortho-substituted \\
\hline
\end{tabular}

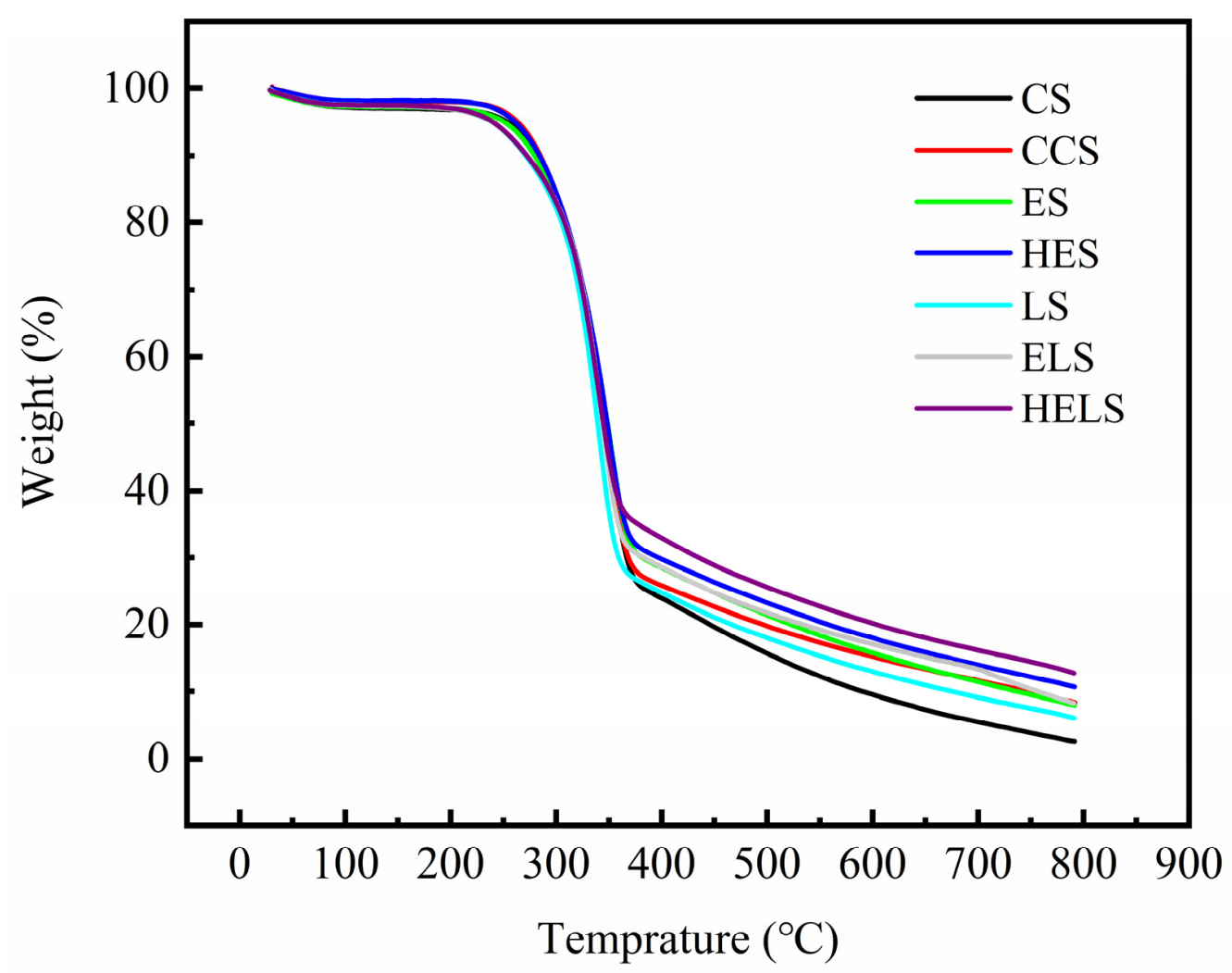

Figure 8. Thermogravimetric analysis of MFP. The temperature was increased from 30 to $795^{\circ} \mathrm{C}$ at a heating rate of $10^{\circ} \mathrm{C} / \mathrm{min}$ under nitrogen atmosphere $(30 \mathrm{~mL} / \mathrm{min})$. 


\subsubsection{Mechanical Properties of MFP}

The mechanical strength plays a key role in the stability for MFP utilization. The mechanical strengths of MFP with different lignin additions are shown in Figure 9a-c. Form the figure, it can be seen that the optimum amount of lignin was $15 \%$.

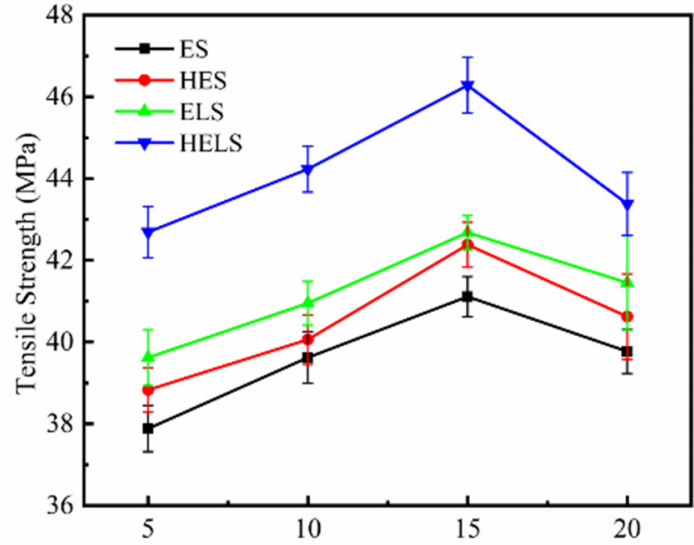

a

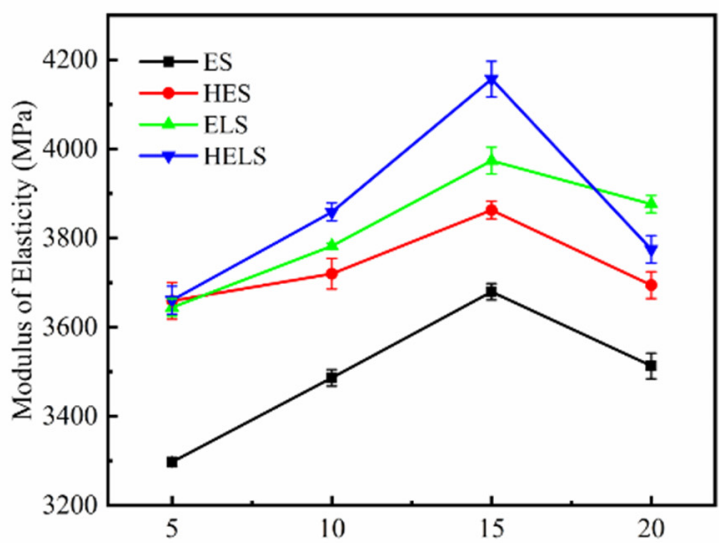

C

Amount of lignin added (\%)

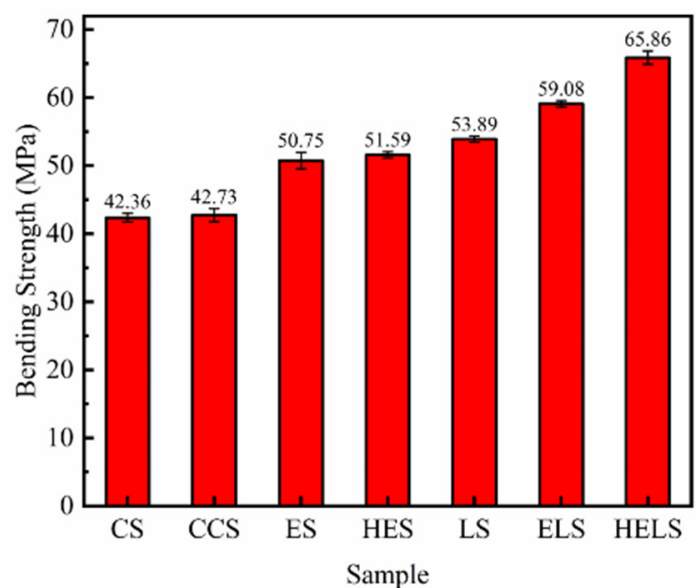

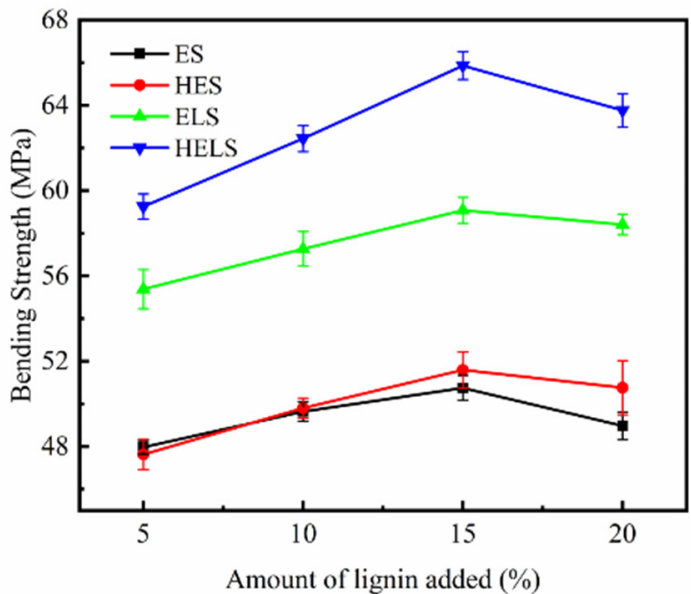
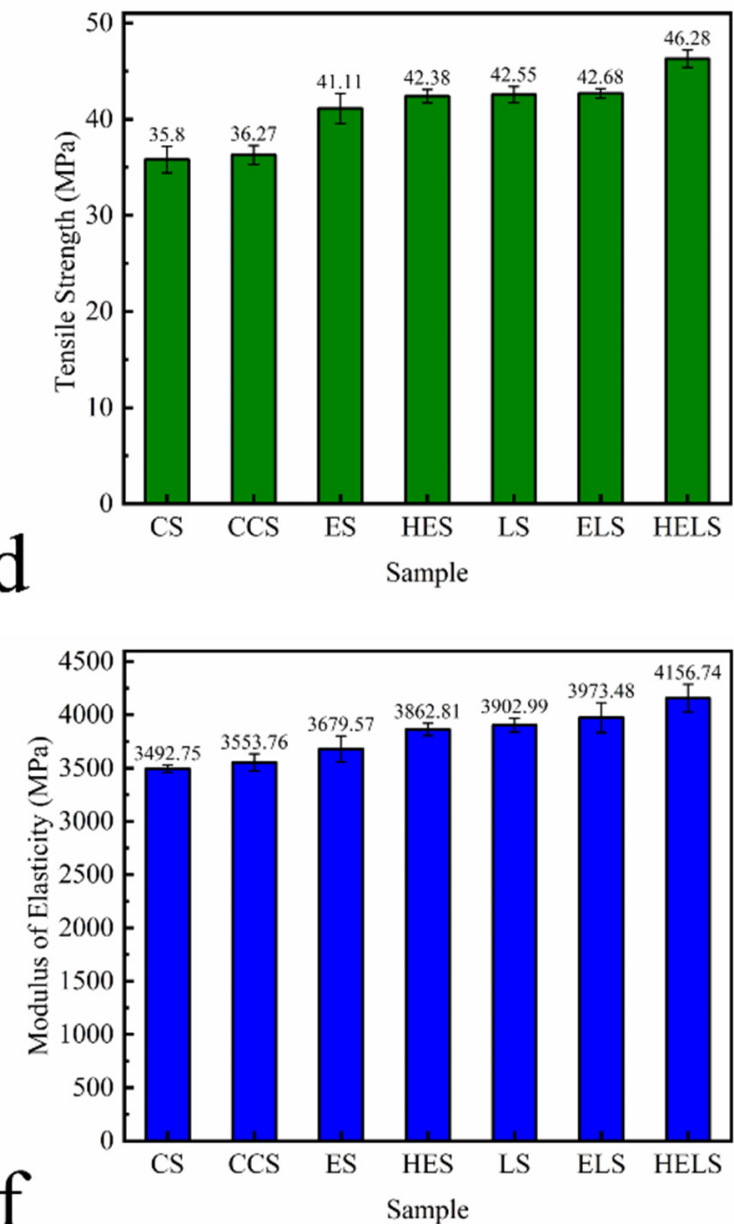

Figure 9. Mechanical Properties of MFP: (a) tensile strength, (b) bending strength, and (c) modulus of elasticity with different amounts of lignin; (d) tensile strength, (e) bending strength, and (f) modulus of elasticity with optimal amount of lignin. All samples were tested using a $1 \mathrm{kN}$ sensor and all data in the Figure 9 are based on three parallel experiments. 
The mechanical strength of each sample for the most appropriate lignin addition is shown in Figure 9d-f. The tensile strength, bending strength, and modulus of elasticity of MFP with 15\% lignin are listed in Table 7. From Figure 9d-f, and Table 7, it can be seen that the addition of CPAM has basically no effect on the mechanical properties of MFP. With the addition of lignin, the tensile strength of ES and HES increased by $14.90 \%$ and $18.42 \%$ and their bending strength was increased by $19.81 \%$ and $21.79 \%$, respectively. The mechanical strength of the MFP prepared with Lewis acid-modified fibers also increased. The enhancement of the mechanical properties is attributed to the conversion of Lewis degraded hemicellulose to furfural and condensation during the molding process. In summary, a substantial improvement of the mechanical properties of the MFP prepared from lignin composite Lewis acid-modified fibers was observed. The tensile and bending strengths of ELS increased by $19.28 \%$ and $39.47 \%$, while those of HELS increased by $29.35 \%$ and $55.55 \%$, respectively. The difference in hydroxyl content of lignin is responsible for the difference in strength. The hydroxyl content of HEHL is higher than that of EHL, resulting in a large amount of resin structure generated during the molding process distributed between the fibers. The presence of the resin structure effectively improved the mechanical properties of the MFP.

Table 7. Mechanical properties of MFPs.

\begin{tabular}{ccccc}
\hline Sample & $\begin{array}{c}\text { Density } \\
\left(\mathbf{g} \cdot \mathbf{c m}^{-\mathbf{3}} \mathbf{)}\right.\end{array}$ & $\begin{array}{c}\text { Tensile Strength } \\
\mathbf{( M P a )}\end{array}$ & $\begin{array}{c}\text { Bending Strength } \\
\mathbf{( M P a )}\end{array}$ & $\begin{array}{c}\text { Modulus of Elasticity } \\
\mathbf{( M P a )}\end{array}$ \\
\hline CS & 0.96 & 35.78 & 42.36 & 3492.75 \\
CCS & 0.94 & 36.27 & 42.73 & 3553.76 \\
ES & 0.93 & 41.11 & 50.75 & 3679.49 \\
HES & 0.96 & 42.37 & 51.59 & 3862.81 \\
LS & 0.97 & 42.55 & 53.89 & 3902.99 \\
ELS & 0.94 & 42.68 & 59.08 & 3973.48 \\
HELS & 0.94 & 46.28 & 65.86 & 4156.74 \\
\hline
\end{tabular}

\subsection{Mechanical Strength Formation Mechanisms}

In order to verify whether the resin structure was generated during the molding process, we compounded polyxylose as a model compound with lignin under the same molding conditions and examined it by 2D-HSQC. The oxygenated aliphatic side chain $\left(\delta_{\mathrm{C}} / \delta_{\mathrm{H}} 45-100 / 2.0-6.0\right)$ and the aromatic $\left(\delta_{\mathrm{C}} / \delta_{\mathrm{H}} 100-150 / 6.0-8.0\right)$ regions of lignin samples and the model compounds are shown in Figure 10. 2D- HSQC cross-peaks were assigned by comparison with those reported in the literature [31-38]. The signal assignments are shown in Table 8 and Figure 11 shows the main lignin and model compound structures identified.

The HSQC spectra corresponding to the aliphatic oxygenated regions $(\delta \mathrm{C} / \delta \mathrm{H} 45-100 /$ 2.0-6.0 ppm) of EHL, HEHL, and model compounds are presented in Figure 10a,c,e, respectively. In Figure $10 \mathrm{a}, \mathrm{c}$, the most abundant inter-unit linkages were of the $\beta-\mathrm{O}-4^{\prime}$ ether-type (structure A, Figure 11), $\beta-5^{\prime}$ type (structure C, Figure 11), and -OMe of EHL and HEHL. In this region, the cross-peaks (Figure 10) and signal assignments (Table 8) are essentially the consistency, but the strength of signals of $\beta-\mathrm{O}-4^{\prime}$ and $-\mathrm{OMe}$ of EHL were higher than HEHL. The phenomenon indicates that the -OMe and $\beta-\mathrm{O}-4$ ether bonds of lignin are broken during the hydroxylation modification process, resulting in a decrease in the molecular weight of lignin. For the model compounds (Figure 10e), within this region only -OMe was present and the signal strength was considered weak compared with EHL and HEHL. This phenomenon indicates that during the hot-pressing process, some chemical bonds of the HEHL are broken or chemically changed to created new chemical bonds.

The HSQC spectra corresponding to the aromatic regions $\left(\delta_{\mathrm{C}} / \delta_{\mathrm{H}} 100-150 / 6.0-8.0 \mathrm{ppm}\right)$ of EHL, HEHL, and model compounds are presented in Figure $10 \mathrm{~b}, \mathrm{~d}, \mathrm{f}$, respectively. In Figure 10b,d, signals from p-hydroxycinnamyl (H), guaiacyl (G), syringyl (S), p-coumarates 
(PCA), and ferulates (FA) units were observed in the EHL and EHL, respectively. And the signal assignments were shown in Table 8. The main cross-signals of the EHL and HEHL essentially the same in this region. However, in Figure 10f, the characteristic signal of furan ring (LF, Table 8, Figure 11) appears in addition to the above cross-signals. From the above analysis, it is clear that hemicellulose is converted to furfural during hot-pressing under Lewis-acid catalytic conditions. In an acidic environment, the phenolic hydroxyl group on the HEHL condenses with furfural generated in Lewis-acid modification process to generate a phenolic resin structure; the generation of this structure improves the mechanical strength of the MFP. The reaction mechanisms are shown in Figure 12.
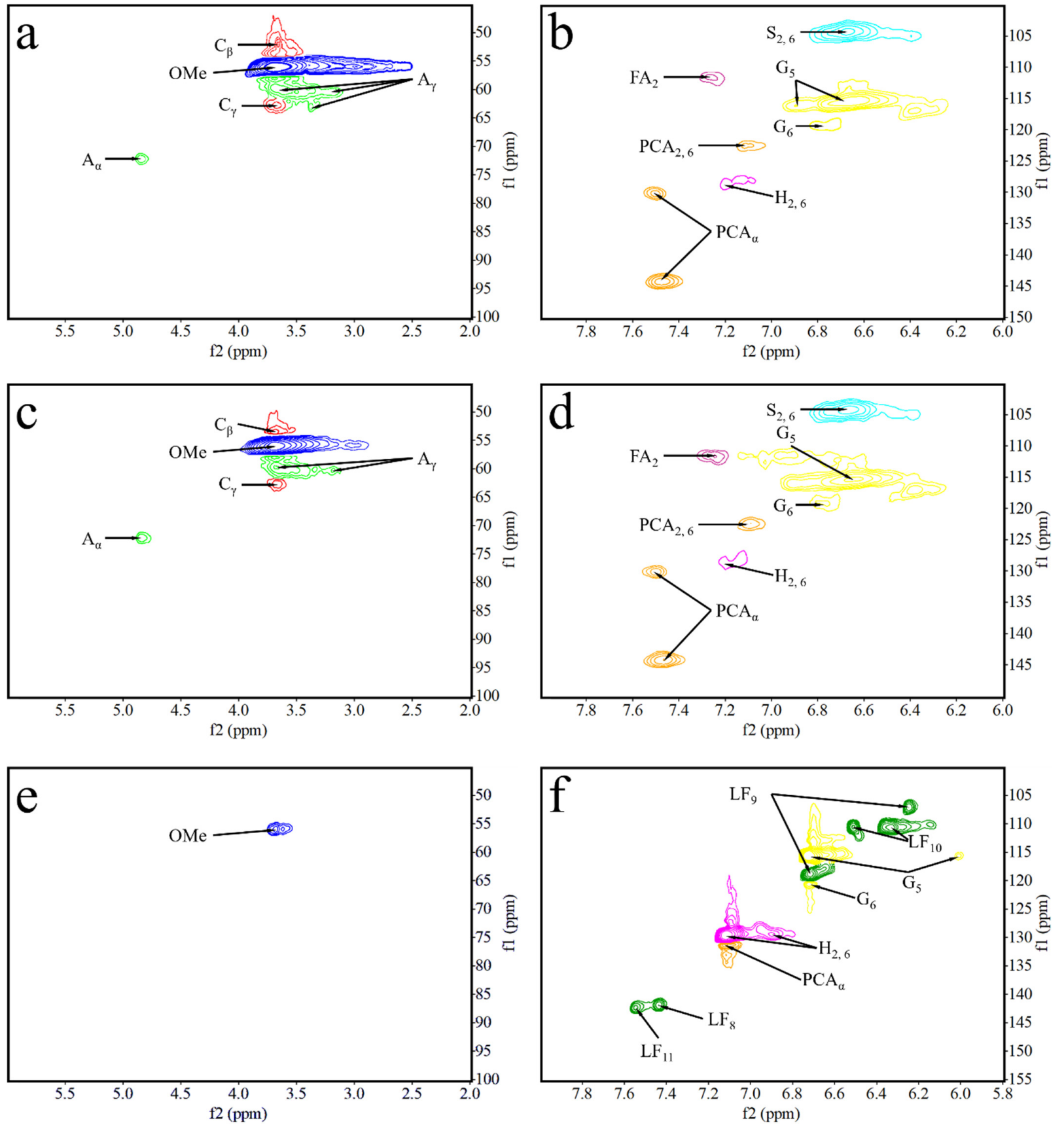

Figure 10. 2D-HSQC spectra of EHL, HEHL, model compounds samples: (a) Side-chain $\left(\delta_{\mathrm{C}} / \delta_{\mathrm{H}} 45-100 / 2.00-6.00\right)$ regions of EHL, (b) aromatic $\left(\delta_{\mathrm{C}} / \delta_{\mathrm{H}} 100-150 / 6.00-8.00\right)$ regions of EHL, (c) Side-chain $\left(\delta_{\mathrm{C}} / \delta_{\mathrm{H}} 45-100 / 2.00-6.00\right)$ regions of HEHL, (d) aromatic $\left(\delta_{\mathrm{C}} / \delta_{\mathrm{H}} 100-150 / 6.00-8.00\right)$ regions of HEHL, (e) Side-chain $\left(\delta_{\mathrm{C}} / \delta_{\mathrm{H}} 45-100 / 2.00-6.00\right)$ regions of model compounds, and (f) aromatic $\left(\delta_{\mathrm{C}} / \delta_{\mathrm{H}} 100-150 / 6.00-8.00\right)$ regions of model compounds. 
Table 8. Assignment of 13C-1H cross-signals in the HSQC spectra of EHL, HEHL, and model compounds.

\begin{tabular}{|c|c|c|c|}
\hline \multirow{2}{*}{ Assignment } & \multicolumn{3}{|c|}{$\delta \mathrm{C} / \delta \mathrm{H}(\mathrm{ppm})$} \\
\hline & EHL & HEHL & Model Compounds \\
\hline $\mathrm{C}_{\beta}-\mathrm{H}_{\beta}$ in phenylcoumarin substructures $\left(\mathrm{C}_{\beta}\right)$ & $53.32 / 3.50$ & $53.59 / 3.67$ & - \\
\hline $\mathrm{C}-\mathrm{H}$ in methoxyls $(-\mathrm{OMe})$ & $56.15 / 3.69$ & $56.08 / 3.69$ & $55.95 / 3.68$ \\
\hline $\mathrm{C}_{\gamma}-\mathrm{H}_{\gamma}$ in $\beta-\mathrm{O}-4^{\prime}$ substructures $\left(\mathrm{A}_{\gamma}\right)$ & $60.38 / 3.59$ & $60.24 / 3.66$ & - \\
\hline- & $60.45 / 3.20$ & $60.56 / 3.20$ & - \\
\hline- & $63.12 / 3.38$ & - & - \\
\hline$C_{\gamma}-C_{\gamma}$ in $\beta-5^{\prime}$ phenylcoumaran substructures $\left(C_{\gamma}\right)$ & $62.93 / 3.67$ & $62.89 / 3.64$ & - \\
\hline $\mathrm{C}_{\alpha}-\mathrm{H}_{\alpha}$ in $\beta-\mathrm{O}-4^{\prime}$ substructures $\left(\mathrm{A}_{\alpha}\right)$ & $72.17 / 4.84$ & $72.11 / 4.83$ & - \\
\hline $\mathrm{C}_{2,6}-\mathrm{H}_{2,6}$ in etherified syringyl units (S) & $104.41 / 6.68$ & $104.17 / 6.67$ & - \\
\hline$\quad \mathrm{C}_{2}-\mathrm{H}_{2}$ in Ferulate (FA) & $111.64 / 7.26$ & $111.60 / 7.25$ & - \\
\hline $\mathrm{C}_{5}-\mathrm{H}_{5}$ in guaicayl units $(\mathrm{G})$ & $115.45 / 6.65$ & $115.32 / 6.65$ & $115.65 / 6.01$ \\
\hline- & $116.10 / 6.90$ & - & $115.65 / 6.72$ \\
\hline $\mathrm{C}_{6}-\mathrm{H}_{6}$ in guaicayl units $(\mathrm{G})$ & $119.51 / 6.79$ & $119.32 / 6.76$ & $120.61 / 6.72$ \\
\hline $\mathrm{C}_{2,6}-\mathrm{H}_{2,6}$ in p-coumarate $(\mathrm{p}-\mathrm{CE})$ & $122.58 / 7.12$ & $122.35 / 7.09$ & - \\
\hline $\mathrm{C}_{2,6}-\mathrm{H}_{2,6}$ in p-hydroxyphenyl units $(\mathrm{H})$ & $128.80 / 7.20$ & $128.80 / 7.2$ & $129.62 / 7.12$ \\
\hline 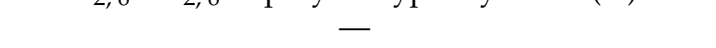 & - & - & $129.52 / 6.90$ \\
\hline $\mathrm{C}_{\alpha}-\mathrm{H}_{\alpha}$ in p-coumarate (p-CE) & $130.20 / 7.50$ & $130.17 / 7.50$ & $131.38 / 7.13$ \\
\hline- & $144.44 / 7.48$ & $144.25 / 7.47$ & - \\
\hline $\mathrm{C}_{8}$ in lignin-furan structure $\left(\mathrm{LF}_{8}\right)$ & - & - & $141.93 / 7.44$ \\
\hline $\mathrm{C}_{9}$ in lignin-furan structure $\left(\mathrm{LF}_{9}\right)$ & - & - & $118.87 / 6.72$ \\
\hline- & - & - & $107.15 / 6.25$ \\
\hline $\mathrm{C}_{10}$ lignin-furan structure $\left(\mathrm{LF}_{10}\right)$ & - & - & $110.56 / 6.51$ \\
\hline- & - & - & $110.66 / 6.33$ \\
\hline $\mathrm{C}_{11}$ lignin-furan structure $\left(\mathrm{LF}_{11}\right)$ & - & - & $142.41 / 7.55$ \\
\hline
\end{tabular}<smiles>CCOc1c(OC)cc(C(O)C(CO)Oc2c(OC)cc(C)cc2OC)cc1OC</smiles>

A<smiles>CCOc1ccc(C(C)O)cc1</smiles>

$\mathrm{H}$<smiles>COc1ccc(C(C)O)cc1OC</smiles>

G<smiles>[X]#[N+]c1cc(OC)c2c(c1)C(CO)C(c1ccc(OC)c(OC)c1)O2</smiles>

$\mathrm{C}$<smiles>COc1cc(C(C)O)cc(OC)c1OC</smiles>

$\mathrm{S}$<smiles>CCOc1ccc(C=CC(=O)O)cc1OC</smiles>

FA<smiles>CCOc1ccc(C=CC(=O)O)cc1</smiles>

PCA

Figure 11. The main structures and linkages in EHL, HEHL, and model compounds: (A) $\beta-\mathrm{O}-4^{\prime}$ structures, (C) resinol structures formed by $\beta-\beta^{\prime}$ coupling, (FA) ferulate units, (PCA) p-coumarate units, (H) p-hydroxyphenyl units, (G) guaiacyl units, (S) syringyl units, and (LF) lignin-furan ring structures. 


\section{Lewis acid modified}

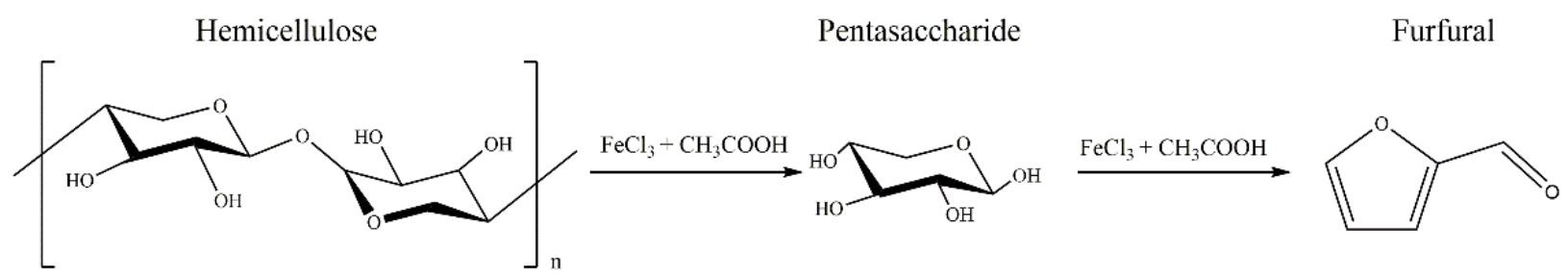

\section{Composite mechanism - HEHL \& Furfural}<smiles>COc1cc([Hg])cc(O)c1O</smiles><smiles>CCCCOc1cc(C(C)c2ccc(OCC(=O)c3cc(OC)c(O)c(C(C)c4ccco4)c3)c(CO)c2)cc(OCCC)c1O</smiles>

Figure 12. Reaction mechanisms that improve the mechanical properties of MFPs.

\section{Technical Challenges of MFPs}

MFPs are widely used as a cushioning material for medical supplies, daily chemical products, and electronic products owing to the abundance of raw material sources, their low price, and their biodegradability. However, the high cost of mold manufacturing has limited the development of MFPs. Therefore, considering its versatility when designing molds will effectively reduce the cost and expand the scope of MFP applications. Furthermore, some manufacturers use primary pulp as raw materials, which increases the production cost and reduces environmental friendliness. This issue could be solved by using secondary fiber as a raw material to produce MFPs. To promote the use of MFPs in the packaging of large size and heavy weight products and equipment, the raw material ratios, mold design, and compounding of other materials should be optimized.

\section{Conclusions}

Based on the results of this study, the following conclusions can be drawn.

1. Upon modification by hydroxylation, the alcohol hydroxyl content, phenolic hydroxyl content, and total hydroxyl content of lignin increased from $2.24 \%$ to $5.18 \%$, from $3.11 \%$ to $4.16 \%$, and from $5.35 \%$ to $9.34 \%$, respectively. Hydrogen peroxide treatment made the surface of lignin powder became smooth, and the molecular weight decreased significantly.

2. HELS prepared from HEHL compounded with Lewis acid-modified fibers showed a slight decrease in density and a significant increase in mechanical strength compared to CS. Its tensile and bending strengths increased from 35.78 to $46.28 \mathrm{MPa}(29.35 \%)$ and from 42.36 to $65.86 \mathrm{MPa}(55.55 \%)$, respectively. Although the thermal stability of HELS was slightly decreased, the increased amount of residual carbon proved that HEHL had been compounded on the surface of Lewis acid-modified fibers and created a resin structure between the fibers, which bonded the fibers more tightly.

3. Milder fiber preparation and modification conditions led to higher mechanical strength of MFP with higher fiber yield and lower production cost, which is beneficial to expand the application of MFPs and lay the foundation for the application of high lignin content fibers. 
Author Contributions: Conceptualization, T.L. and J.Y.; methodology, T.L., Y.W. and J.Y.; validation, T.L. and J.Z.; formal analysis, T.L. and M.L.; investigation, Y.W. and J.Z.; resources, M.L.; data curation, T.L.; writing—original draft preparation, T.L., Y.W. and J.Y.; writing一review and editing, T.L. and J.Y. All authors have read and agreed to the published version of the manuscript.

Funding: This research received no external funding.

Institutional Review Board Statement: Not applicable.

Informed Consent Statement: Not applicable.

Data Availability Statement: The data presented in this study are available on request from the corresponding author.

Acknowledgments: The author expresses his heartfelt thanks to the Northeast Forestry University, Key Laboratory of Bio-based Material Science \& Technology (Northeast Forestry University), Ministry of Education for their full support.

Conflicts of Interest: The authors declare no conflict of interest.

\section{References}

1. Saratale, G.D.; Oh, M.-K. Improving alkaline pretreatment method for preparation of whole rice waste biomass feedstock and bioethanol production. RSC Adv. 2015, 5, 97171-97179. [CrossRef]

2. Saratale, G.D.; Jung, M.Y.; Oh, M.K. Reutilization of green liquor chemicals for pretreatment of whole rice waste biomass and its application to 2,3-butanediol production. Bioresour. Technol. 2016, 205, 90-96. [CrossRef]

3. Tayeb, A.H.; Amini, E.; Ghasemi, S.; Tajvidi, M. Cellulose Nanomaterials-Binding Properties and Applications: A Review. Molecules 2018, 23, 2684. [CrossRef] [PubMed]

4. Didone, M.; Saxena, P.; Brilhuis-Meijer, E.; Tosello, G.; Bissacco, G.; McAloone, T.C.; Pigosso, D.C.A.; Howard, T.J. Moulded Pulp Manufacturing: Overview and Prospects for the Process Technology. Packag. Technol. Sci. 2017, 30, 231-249. [CrossRef]

5. Kong, W.Q.; Wang, C.W.; Jia, C.; Kuang, Y.D.; Pastel, G.; Chen, C.J.; Chen, G.G.; He, S.M.; Huang, H.; Zhang, J.H.; et al. Muscle-Inspired Highly Anisotropic, Strong, Ion-Conductive Hydrogels. Adv. Mater. 2018, 30, 7. [CrossRef] [PubMed]

6. Hosseini, S.B.; Hedjazi, S.; Jamalirad, L. Investigation on physical and mechanical properties of pulp-plastic composites from bagasse. Wood Mater. Sci. Eng. 2017, 12, 279-287. [CrossRef]

7. Lange, C.; Touaiti, F.; Fardim, P. Hybrid clay functionalized biofibres for composite applications. Compos. Part B Eng. 2013, 47, 260-266. [CrossRef]

8. Lerche, H.; Benthien, J.T.; Schwarz, K.U.; Ohlmeyer, M. Effects of Defibration Conditions on Mechanical and Physical Properties of Wood Fiber/High-Density Polyethylene Composites. J. Wood Chem. Technol. 2014, 34, 98-110. [CrossRef]

9. Joseleau, J.P.; Chevalier-Billosta, V.; Ruel, K. Interaction between microfibrillar cellulose fines and fibers: Influence on pulp qualities and paper sheet properties. Cellulose 2012, 19, 769-777. [CrossRef]

10. Wang, J.J.; Wang, B.; Liu, J.L.; Ni, L.; Li, J.Z. Effect of Hot-Pressing Temperature on Characteristics of Straw-Based Binderless Fiberboards with Pulping Effluent. Materials 2019, 12, 922. [CrossRef] [PubMed]

11. Rowell, R.M.; McSweeny, J.D. Heat treatments of wood fibers for self-bonding and stabilized fiberboards. Mol. Cryst. Liq. Cryst. 2008, 483, 307-325. [CrossRef]

12. Wang, Q.L.; Xiao, S.L.; Shi, S.Q.; Cai, L.P. Mechanical Strength, Thermal Stability, and Hydrophobicity of Fiber Materials after Removal of Residual Lignin. BioResources 2018, 13, 71-85. [CrossRef]

13. Pu, Y.Q.; Cao, S.L.; Ragauskas, A.J. Application of quantitative P-31 NMR in biomass lignin and biofuel precursors characterization. Energy Environ. Sci. 2011, 4, 3154-3166. [CrossRef]

14. Chow, S. Adhesive developments in forest products. Wood Sci. Technol. 1983, 17, 1-11. [CrossRef]

15. Widsten, P.; Murton, K.; West, M. Production of 5-hydroxymethylfurfural and furfural from a mixed saccharide feedstock in biphasic solvent systems. Ind. Crop. Prod. 2018, 119, 237-242. [CrossRef]

16. Zhang, Y.S.; Yuan, Z.S.; Mahmood, N.; Huang, S.H.; Xu, C. Sustainable bio-phenol-hydroxymethylfurfural resins using phenolated de-polymerized hydrolysis lignin and their application in bio-composites. Ind. Crop. Prod. 2016, 79, 84-90. [CrossRef]

17. Kalami, S.; Arefmanesh, M.; Master, E.; Nejad, M. Replacing $100 \%$ of phenol in phenolic adhesive formulations with lignin. J. Appl. Polym. Sci. 2017, 134, 9. [CrossRef]

18. Wang, F.; Kuai, J.T.; Pan, H.S.; Wang, N.N.; Zhu, X.B. Study on the demethylation of enzymatic hydrolysis lignin and the properties of lignin-epoxy resin blends. Wood Sci. Technol. 2018, 52, 1343-1357. [CrossRef]

19. Liu, W.F.; Fang, C.; Wang, S.Y.; Huang, J.H.; Qiu, X.Q. High-Performance Lignin-Containing Polyurethane Elastomers with Dynamic Covalent Polymer Networks. Macromolecules 2019, 52, 6474-6484. [CrossRef]

20. Zhu, S.Y.; Chen, K.F.; Xu, J.; Li, J.; Mo, L.H. Bio-based polyurethane foam preparation employing lignin from corn stalk enzymatic hydrolysis residues. RSC Adv. 2018, 8, 15754-15761. [CrossRef] 
21. Ziebell, A.; Gracom, K.; Katahira, R.; Chen, F.; Pu, Y.Q.; Ragauskas, A.; Dixon, R.A.; Davis, M. Increase in 4-Coumaryl Alcohol Units during Lignification in Alfalfa (Medicago sativa) Alters the Extractability and Molecular Weight of Lignin. J. Biol. Chem. 2010, 285, 38961-38968. [CrossRef] [PubMed]

22. Zhang, J.; Liu, W.; Han, S.; Hou, Q.; Li, Y.; Wang, Y.; Long, Z. Effect of Industrial Grade MgO with Different Particle Sizes on the Bleaching of Poplar Chemi-Thermomechanical Pulp. Ind. Eng. Chem. Res. 2013, 52, 7645-7650. [CrossRef]

23. Araujo, L.C.P.; Yamaji, F.M.; Lima, V.H.; Botaro, V.R. Kraft lignin fractionation by organic solvents: Correlation between molar mass and higher heating value. Bioresour. Technol. 2020, 314, 7. [CrossRef]

24. Rover, M.R.; Brown, R.C. Quantification of total phenols in bio-oil using the Folin-Ciocalteu method. J. Anal. Appl. Pyrolysis 2013, 104, 366-371. [CrossRef]

25. Faix, O. Classification of Lignins from Different Botanical Origins by FT-IR Spectroscopy. Holzforsch 1991, 45, 21-28. [CrossRef]

26. Xu, F.; Sun, R.-C.; Zhai, M.-Z.; Sun, J.-X.; Jiang, J.-X.; Zhao, G.-J. Comparative study of three lignin fractions isolated from mild ball-milled Tamarix austromogoliac and Caragana sepium. J. Appl. Polym. Sci. 2008, 108, 1158-1168. [CrossRef]

27. Yan, L.C.; Cui, Y.H.; Gou, G.J.; Wang, Q.; Jiang, M.; Zhang, S.L.; Hui, D.; Gou, J.H.; Zhou, Z.W. Liquefaction of lignin in hot-compressed water to phenolic feedstock for the synthesis of phenol-formaldehyde resins. Compos. Part B Eng. 2017, 112, 8-14. [CrossRef]

28. Yuan, Z.S.; Zhang, Y.S.; Xu, C. Synthesis and thermomechanical property study of Novolac phenol-hydroxymethyl furfural (PHMF) resin. RSC Adv. 2014, 4, 31829-31835. [CrossRef]

29. Zhang, N.; Li, Z.; Xiao, Y.; Pan, Z.; Jia, P.; Feng, G.; Bao, C.; Zhou, Y.; Hua, L. Lignin-based phenolic resin modified with whisker silicon and its application. J. Bioresour. Bioprod. 2020, 5, 67-77. [CrossRef]

30. Zhang, Y.; Li, N.; Chen, Z.; Ding, C.; Zheng, Q.; Xu, J.; Meng, Q. Synthesis of High-Water-Resistance Lignin-Phenol Resin Adhesive with Furfural as a Crosslinking Agent. Polymers 2020, 12, 2805. [CrossRef] [PubMed]

31. Jiang, X.; Savithri, D.; Du, X.Y.; Pawar, S.; Jameel, H.; Chang, H.M.; Zhou, X.F. Fractionation and Characterization of Kraft Lignin by Sequential Precipitation with Various Organic Solvents. ACS Sustain. Chem. Eng. 2017, 5, 835-842. [CrossRef]

32. Jiang, B.; Cao, T.Y.; Gu, F.; Wu, W.J.; Jin, Y.C. Comparison of the Structural Characteristics of Cellulolytic Enzyme Lignin Preparations Isolated from Wheat Straw Stem and Leaf. ACS Sustain. Chem. Eng. 2017, 5, 342-349. [CrossRef]

33. Yuan, T.Q.; Sun, S.N.; Xu, F.; Sun, R.C. Characterization of Lignin Structures and Lignin-Carbohydrate Complex (LCC) Linkages by Quantitative C-13 and 2D HSQC NMR Spectroscopy. J. Agric. Food Chem. 2011, 59, 10604-10614. [CrossRef] [PubMed]

34. Ando, D.; Ralph, J. Method to Regioselectively Iodine-Tag Free-Phenolic Aromatic End-Groups in Lignin for H-1-C-13-HSQC NMR Analysis. ACS Sustain. Chem. Eng. 2019, 7, 18624-18629. [CrossRef]

35. Reyes-Rivera, J.; Soto-Hernandez, M.; Canche-Escamilla, G.; Terrazas, T. Structural Characterization of Lignin in Four Cacti Wood: Implications of Lignification in the Growth Form and Succulence. Front. Plant Sci. 2018, 9. [CrossRef] [PubMed]

36. Rio, J.C.D.; Prinsen, P.; Rencoret, J.; Nieto, L.; Jimenez-Barbero, J.; Ralph, J.; Martinez, A.T.; Gutierrez, A. Structural Characterization of the Lignin in the Cortex and Pith of Elephant Grass (Pennisetum purpureum) Stems. J. Agric. Food Chem. 2012, 60, 3619-3634. [CrossRef] [PubMed]

37. Mu, W.; Ben, H.X.; Newalkar, G.; Ragauskas, A.; Qiu, D.M.; Deng, Y.L. Structure Analysis of Pine Bark-, Residue-, and StemDerived Light Oil and Its Hydrodeoxygenation Products. Ind. Eng. Chem. Res. 2014, 53, 11269-11275. [CrossRef]

38. Asmafiliz, N.; Kilic, Z.; Hayvali, Z.; Acik, L.; Hokelek, T.; Dal, H.; Oner, Y. Phosphorus-nitrogen compounds. Part 23: Syntheses, structural investigations, biological activities, and DNA interactions of new N/O spirocyclotriphosphazenes. Spectrochim. Acta Part A Mol. Biomol. Spectrosc. 2012, 86, 214-223. [CrossRef] [PubMed] 